\section{INTERNATIONAL SYSTEMS AND STANDARDS*}

\author{
By SIR RICHARD GREGORY, Bt., F.R.S.
}

$\mathrm{T}$ HE Great Exhibition of 1851, in Hyde Park, London, was the pioneer of international exhibitions, and it demonstrated the industrial resources of the nations which took part in it as well as the extent of world markets in them. The International Exhibition held in London eleven years later led to the formation of the International Working Men's Association, now known as "The International", at a great public meeting in 1864 of artisans from many countries, and thus brought conditions of labour into the economic field. In the following year an International Telegraph Convention was held to regularize systems of transmitting telegraphic signals, and in 1874 the General Postal Union was formed. These were the beginnings of international trade associations, unions and relationships. The Postal Union is the best example of organization of systems and standards on an international basis. For its service the world is the unit and there are no separate territories or boundaries.

It is necessary for manufacturers to adopt and maintain standards of measurement for their products, whether for domestic or for foreign trade. Standardization within and between industries leads to better understanding and co-operation in the common interests of the producer and the consumer. It is increasingly important for the maintenance and development of foreign trade and is the best means of ensuring fairness of exchange and facilitating industrial operations. After the War of 1914-18, one of the outstanding developments in the chief indus. trial countries, and perhaps more particularly in Great Britain and the United States, was that of co-operation in standardization of products of allied or related industries on a national scale.

So far back as the beginning of this century, a small group represønting eivil, mechanical and electrical engineering was set up in Great Britain as the British Engineering Standards Association, which was incorporated by Royal Charter in 1929 and is now the British Standards Institution. There are two kinds of standardization-one concerned with fundamental standards and units of measurement, and the other with the rather wider field of industrial simplification and uniformity. The latter involves the adoption of standard specifications of material and method in all branches of industry where they can be usefully applied; and they are constantly being added to and revised to meet new industrial needs.

For inter-Imperial trade it is desirable to have common agreement upon standards of measurement based upon the British system of weights and measures. The British Standards Institution exists to ensure this uniformity of principles and practice of standardizing bodies in all parts of the Empire. It has also the duty of converting British standard specifications into those of other countries having standardized systems, in order to facilitate foreign trade. As, however, the tendency for many years has been towards the adoption of the metric system in new industries, and this system is already used in most countries of the world, there is every reason to believe that it will becorne truly international in its

* From an address to the Association of Special Librarles and Information Bureaux, delivered on November 7. service and that national and Imperial standards will have to be adapted to it for purposes of world trade. In recent years the scope of the work of the Institution has been very greatly enlarged, and at the present time it covers much work on rationalization and simplification, with special reference to war-time needs in relation to materials in short supply and the use of substitutes.

The use of scientific principles as the basis of measurement came under consideration in the early days of electrical engineering. A century ago there was no settled system for the measurement and statement of electrical quantities, and all electrical measurements were merely comparisons between magnitudes of the same kind. The resistance of one conductor could be compared with that of a particular piece of wire and the electromotive force of one battery could be compared with that of another, but there were no recognized relationships between these quantities or fundamental standards to represent them. The German physicist, W. E. Weber, conceived the idea of expressing the value of any electrical quantity without reference to any quantity of the same kind, and in terms not involving any physical constants except the units of length, mass and time.

The British Association took up the subject in 1861 at the suggestion of Lord Kelvin, and the result of reports of its committee was the establishment of the coherent system now adopted everywhere in science and engineering. After much discussion and correspondence, it was decided to adopt the centimetre, the gram and the second as the primary units of length, mass and time to which the various quantities used in electrical measurements could be referred. This is the c.G.S. system. and all values of electrical quantities are expressed in these units. For practical purposes, standards of electrical resistance, current, electromotive force and power have been adopted by international conferences as particular magnitudes of the centimetre, gram and second. Germany, France, Italy and Great Britain are respectively represented in the names of these fundamental electrical units by ohm, ampere, volt (Volta) and watt.

Several years ago, Prof. G. Giorgi, of the University of Palermo, proposed a new system of electrical units based upon the metre, kilogram and second (the M.K.s. system), and the International Electrotechnical Commission recommended in 1938 that this system should be adopted in all countries. The system is in no way antagonistic to the C.G.S. system, and for instructional and practical purposes it has decided advantages in simplifying relationships between fundamental electrical, mechanical and magnetic units.

In science, and to an increasing extent in engineering, measurements are usually expressed in the international units of length, mass and time. For each of these fundamental quantities it is necessary to have a primary standard of reference. The primary standards of length and mass are kept at the International Bureau of Weights and Measures at Sèvres, near Paris. They are the International Prototype Metre and the International Prototype Kilogramme. The centimetre is $1 / 100$ of the standard metre, and the gram 1/1000 of the standard kilogram. The standard international unit of time is one second, or the 86,400 th part of the mean solar day.

With the introduction of reilway systems, a standard time had to be adopted for the time-tables of trains. In Great Britain the standard time adopted 
was that of Greenwich; in the United States, where local times differ by several hours from one another, it was impracticable to use a single time standard for the whole country. The running of long-distance trains in times which differed greatly in different States was so confusing that a remedy had to be found; and it was produced by a Scots Canadian, Sir Sandford Fleming, in 1878. His proposal was to legalize a universal day, beginning at mean noon of Greenwich time, the hours being counted 0 hour to 24 hours. A few years later a conference held at Washington approved the adoption of a single prime meridian, and also Sir Sandford Fleming's principle of dividing the whole earth into twenty-four time zones, each separated from the next by one hour. This zone system of daily time reckoning on a uniform and universal plan has become truly international and has superseded by fixed standards the medley of prime meridians and local times which kept peoples apart and hindered the development of their common interests.

The division of the whole interval of day and night into twenty-four parts or hours, each of which was subdivided into parts like minutes and seconds, goes back to Babylonian times six thousand or so years ago. (The division of the angles in a circle into 60 by 60 or 360 degrees has the same origin.) The day and. the night were each given a duration of twelve hours, but the lengths of the hours differed locally and with the seasons. With the introduction of clocks, it became necessary to establish a standard time interval independent of the varying lengths of the local day from one solar noon to the next. The average interval between successive noons became this standard as the mean solar day, which is the common day of civil life, and gives rise to mean solar time, or mean time. From about the end of the eighteenth century, mean time has been used in most countries instead of local solar time.

The standard time of a country or region is reckoned from a particular meridian, as it would be confusing to use a number of mean local times. Since the adoption of the zone system, standard times are referred to twenty-four meridians separated from Greenwich by a certain number of hours, with the zero hour at midnight and reckoned up to twenty-four hours, or in Great Britain up to twelve hours antemeridian and twelve post-meridian. For practical purposes, the rotation of the earth upon its axis is invariable, and so is that of the second, or $1 / 86,400$ part of a day, derived indirectly from it. The unit measure of time is, therefore, the same in all countries.

Various standards of measurement of length and mass (or weight) are in everyday use in different parts of the world and they impede foreign trade transactions because of their number and complication. In 1875, an International Conference on Weights and Measures fixed the standards of the International Metric System, and the International Bureau at Sèvres was afterwards established to preserve them. All scientific measurements are expressed in terms of the metric system, and in most countries the use of this system of weights and measures has been adopted. It was legalized in Great Britain in 1897, but was not made compulsory, though many Chambers of Commerce and other organizations have often urged its adoption, and the Decimal Association has persistently carried on a campaign in favour of it. Developments of mechanical engineering have, however, made a large general public familiar with a number of metric measures. Radio wave-lengths are expressed in metres, motor-car and aeroplane parts in millimetres or other subdivisions of the metre, and bores of guns and similar ordnance dimensions in the same decimalized units.

The metric system of weights and measures is truly the only system which can claim to be international in its scope and standards; and its use is likely to be extended after the present War. It does not matter much what standards, or values are used for special trade or commercial transactions within customary regions or countries, but for business outside such areas, or with other peoples, fixed mercantile standards of an international kind are essential, and those of the metric system have been proved by adoption in most countries of the world to provide what is needed for international business.

In establishing the metric system on the Arabic scale of numerical notation and extending it to decimal fractions, French men of science at the close of the eighteenth century used the best methods of easy reckoning known in the history of mathematies. Their system also provided for a simple and uniform scale of relationships between the multiples and submultiples of the standard instead of the varying and unrelated quantities preserved in such tables as those of British weights and measures, upon which so much time has to be wasted in school and in everyday calculations.

By adopting the decimal scale of notation in the metric system the founders of the system used a natural plan of counting based upon the ten fingers of human hands and customary among more peoples than any other scale. A duodecimal scale has certain advantages over a decimal scale, as it permits simpler expression of halves, thirds and quarters, but it is futile to suggest the general adoption of a twelve or dozen scale either for national or international use. Whatever system of reckoning is used to express numbers and fractions, quantities will continue to be divided into halves, quarters and so on in everyday speech and practice, and new standards of weights and measures will be thought of in old denominations both locally and nationally.

As science is an international study, there must be common standards and units of measurement in all its branches in order to ensure uniform systems of comparison of results. After the discovery of radium and other radioactive elements, it became necessary to give quantitative values to their properties and to express them in agreed units. This was done by an International Radium Standards Commission, which adopted the quantity of radium emanation (radon) in equilibrium with one gram of radium as the standard unit and gave the name Curie to it. Units of physical science have thus entered the field of radioactive therapy.

One of the many useful services rendered by the Health Organization of the League of Nations has been the establishment and supply, on an international basis, of a series of 'standards of reference' by means of which the potency of many important specific agents used in medicine can be accurately determined and expressed in a commonly accepted system of notation. The series comprises standards for the assay of the antitoxins, the arsphenamines, the vitamins, insulin, the active principle of the posterior lobe of the pituitary body, many of the newly introduced sex hormones and the heart drugs.

Before the War, the international biological standards for the arsphenamines, vitamins, hormones and heart drugs were maintained at the National Institute for Medical Research, Hampstead, London, 
and those for the antitoxins and tuberculin at the State Serum Institute, Copenhagen. After the occupation of Denmark, the League of Nations asked the Medical Research Council to undertake the supply of the standards for the antitoxins and tuberculin to those countries which had hitherto received these essential materials from Copenhagen. More recently, an international standard for vitamin $\mathbf{E}$ has been established and made available, and the work towards the establishment of a standard for the important anticoagulent, heparin, has been completed.

\section{A World Language}

Primitive man was able to represent objects and motions by drawings, and by doing so he used a sign language understood by all peoples. Sir Richard Paget, who has devoted much attention to this subject, has shown that the close relationship between the movements of the hand and mouth would associate the symbolizing of objects with sounds and gestures, and thus combine art and emotional expression in a sign language. The representation of objects is still preserved in the Chinese writing of a few characters, and in the infancy of the language two or more characters were combined to suggest $a$ third thing or idea. The Chinese language was afterwards built up of characters representing sounds or phonograms instead of pictorial symbols or ideographs. An educated Chinese to-day will, however, draw ideographs to be read by a fellow countryman who speaks a different dialect.

Drawings provide a universal means of representing objects, and their characters also convey individual or composite emotions and meanings. Many early forms of writing are conventional characters developed from pictographs of this kind, and out of these conventionalized marks alphabets were constructed or characters were combined to represent syllables. All human beings express certain emotions, such as anger and fear, by much the same sounds, signs and gestures, and all can interpret simple picture writing, as all can understand themeaning of actions reproduced in moving pictures, silent or sound. There are, however, many conventionalized forms of characters to represent these sounds and thoughts by written or printed words, and these combinations make up the many languages of the world.

Among the important problems of an international kind to be promoted now and after the War is that of a means of expression in a language easily learnt and used by all civilized peoples of the world. The International Morse Code of signals is an example of an accepted system of alphabetical and numerical communication, and what is wanted now is an auxiliary vehicle of language which will be as widely understood. The subject of an international auxiliary language has long been under discussion, but we seem to be no nearer agreement as to what this language should be than we were after the War of 1914-18. In 1921, the British Association published a careful and comprehensive report on this subject, prepared by a committee representing humanistic as well as scientific interests, and in collaboration with the chief associations concerned with classical and modern languages as well as by consultation with a number of learned societies.

The British Association Committee was appointed after the International Research Council, at a meeting in Brussels in 1919, had taken up the question of an international auxiliary language and recommended the formation of an international committee to inquire into the position and outlook of the subject. It was hoped that a central internationalorganization would be formed, under the League of Nations, and be empowered to make the final selection of the international auxiliary language, if feasible, and to take measures to ensure for it the greatest possible degree of stability. Chairmen were appointed to represent national committees for France, Italy, Japan and Belgium, and the chairman of the British Association Committee undertook to represent Great Britain on the Committee of the International Research Council.

The desirability of an international auxiliary language having been unanimously approved by the British Association Committee, attention was given to the advantages and disadvantages of the following three types : (1) a dead language, for example, Latin ; (2) a national language, for example, English ; (3) an invented or artificial language, for example, Esperanto or Tdo.

The claims for the use of each of these languages as an international auxiliary language were justly and concisely stated by their own specialists in the report of the Committee. After careful consideration of this and other evidence from high authorities at home and abroad, the Committee found itself unable to pronounce judgment in favour of a particular auxiliary language for international use. The conclusions reached may be expressed as follows: (1) Latin is too diffcult to serve as an international auxiliary language, and its advantages are outweighed by its disadvantages. (2) The great international languages of the past have all borne the marks of imperial prestige which prevented them from being welcomed by alien races. 'The adoption of any modern national language by the common consent of the chief nations is therefore unlikely, as it would confer undue advan. tages and excite jealousy, however impartial the promoters of the language might be. (3) Invented languages constructed on scientific principles and adaptable to many diverse requirements are practicable means of international communication. They are neutral and have advantages of simplicity not possessed by most national languages. What auxiliary language of this kind will meet with general approval remains to be decided by international agreement.

In the interest of international communication and the free expression of ideas, it is to be hoped that academic as well as scientific and commercial organizations will assist in the movement towards an agreed auxiliary language. A committee of the British Association on post-war university education has dealt with the subject recently in one of the sections of its report. It recommends that apart altogether from the academic study of language and literature, every university should require its students to be able to make themselves understood, by speech and writing, in an auxiliary international language. The Committee suggests that the Universities Bureau of the British Empire, in consultation with the American Universities Bureau and the Association of University Professors and Lecturers of Allied Countries in Great Britain, could take up the subject very appropriately and prepare a report upon it. There is no better way of promoting interrelationships between the peoples of the world than that of a simple common language; and the construction of such an instrument should not be beyond the powers of responsible authorities-literary, scientific and commercial-working together in a common and needful purpose. 